BULLETIN Bulletin hispanique

HISPANIQUE Université Michel de Montaigne Bordeaux

111-1 | 2009

Varia

\title{
Luis Bagué Quilez, Poesía en pie de paz. Modos del compromiso hacia el tercer milenio
}

Pre-Textos, Valencia, 2006

\section{Claude Le Bigot}

\section{(2) OpenEdition}

\section{Journals}

Edición electrónica

URL: http://journals.openedition.org/bulletinhispanique/976

DOI: 10.4000/bulletinhispanique.976

ISSN: 1775-3821

\section{Editor}

Presses universitaires de Bordeaux

\section{Edición impresa}

Fecha de publicación: 1 junio 2009

Paginación: 290-304

ISBN: 978-2-86781-586-7

ISSN: 0007-4640

\section{Referencia electrónica}

Claude Le Bigot, «Luis Bagué Quilez, Poesía en pie de paz. Modos del compromiso hacia el tercer milenio », Bulletin hispanique [En línea], 111-1 | 2009, Publicado el 10 julio 2012, consultado el 21 septiembre 2020. URL : http://journals.openedition.org/bulletinhispanique/976 ; DOI : https://doi.org/10.4000/ bulletinhispanique.976 
Luis Bagué Quilez, Poesía en pie de paz. Modos del compromiso hacia el tercer milenio. - Valencia, Pre-Textos, 2006, 408 p. - ISBN : 84-8191-789-3.

La cuestión del compromiso en literatura tuvo contornos bastante bien delineados mientras se mantuvieron en vida los discursos de legitimación, a partir de los cuales los estudiosos de teoría literaria sacaban sus criterios de lectura ; incluso aportaron su ayuda los linguistas, especialmente los adeptas de la pragmática que pretendían facilitar las herramientas para determinar el grado de eficacia de la palabra literaria en el campo de la política. Pero años de estructuralismo a lo Roland Barthes contribuyeron no poco a poner en tela de juicio la capacidad impactante de la literatura en el terreno político y aceleró el descrédito de la littérature engagée, en el momento en que en España ésta seguía teniendo cierta vigencia, especialmente en el campo poético, acaso gracias a sus resonancias a través de la canción de protesta. Pero la ola del culturalismo produjo un efecto demoledor, con el rechazo tajante de cualquier sumisión de la creación a un credo ideológico. Esto fue en las postrimerías del franquismo. Ya instalada la democracia en Espańa, nadie puede negar que está de vuelta la cuestión del compromiso -ya no en el sentido gramsciano de posturas defendidas por el intelectual orgánicosino como discurso crítico que la literatura puede mantener sobre el estado del mundo, la realidad social y sobre las opiniones políticas, reactivada de manera masiva en el campo de la novela si consideramos cómo la ficción se ha nutrido con las relaciones entre historia y memoria. Tampoco puede decirse que la poesía quede al margen del fenómeno ya que reanuda con formas de compromiso que no se limitan a las proclamas y producciones de los colectivos (Feroces, Alicia bajo cero...) sino que surgen bajo nuevas formas de escrituras, dándole al discurso lírico una fuerza impactante a la que había renunciado.

Esta es la problemática que Luis Bagué Quílez desarrolla en un volumen de 400 apretadas páginas, fruto de una tesis doctoral, bajo el título de Poesía en pie de paz, claro guiño de ojo hacia un poema monteriano ${ }^{3}$, completado por un subtítulo que aclara el contenido: Modos del compromiso hacia el tercer milenio. Con este trabajo ${ }^{4}$, el autor se granjeó el VI Premio Internacional «Gerardo Diego » de Investigación Literaria de 2006. Y forzoso es reconocer que el libro constituye un aporte fundamental a la historia del compromiso literario, llevado con rigor teórico y amplia documentación, apuntalada

3. Cf. "En pie de paz ", poema de Luis García Montero recogido en Además, Madrid, Poesía Hiperión, 1994, p. 65.

4. Luis Bagué Quílez, Poesía en pie de paz. Modos del compromiso hacia el tercer milenio. Valencia, Pre-Textos, 2006. 
la reflexión teórica por el análisis detallado de "cuatro aproximaciones al compromiso en la poesía española reciente "(J. Riechmann, R. Wolfe, F. Beltrán, L. García Montero). Partiendo de lo general hacia lo particular, L. Bagué Quílez enfoca su acercamiento al compromiso de la actual poesía española desde el marco de la cultura posmoderna, que acabó, alrededor del 68, con el reino de las certezas absolutas. No sólo coincide este período con el final de los grandes discursos de legitimación o sea el hundimiento de las ideologías, sino que acompaña la crisis del racionalismo, la muerte del sujeto, las flaquezas de la interpretación, la inoperancia social del arte. Las teorías más radicales como las de Francis Fukuyama anuncian el fin de la Historia (1992). En España, Josep Fontana criticó las posturas de Fukuyama, hablando sólo de un hipotético debilitamiento de la ciencia histórica ${ }^{5}$. Pero, a nivel filosófico, la oposición más fuerte procedió de Jürgen Habermas para quien la modernidad no está agotada al final de su trayecto racionalista ; abogaba a favor de un retorno a la Historia, la mejor referencia para garantizar la defensa de la democracia. Preconiza el diálogo entre modernidad y posmodernidad, capaz de preservar el carácter universal de la razón. Luis Bagué se ciñe totalmente a este marco epistemológico para enfocar la vuelta de la lírica española al compromiso : "El programa de Habermas resultaba muy atractivo para adaptarlo a la lírica española de la década de los ochenta" (LB, 31) ${ }^{6}$.

Bajo los auspicios de la postmodernidad, Luis Bagué deslinda los contornos de las grandes corrientes líricas que afectan a los poetas de los años 80 y 90 (capítulo II). Si hoy en día los historiadores de la poesía admiten que la irrupción de los novísimos significó una auténtica ruptura frente a la poesía social (cuyas evoluciones y disidencias no fueron consideradas por los novísimos ${ }^{7}$ ), no tardó en fisurarse el frente del rechazo ; tan sólo ostentaba una unidad de fachada, por obedecer a estéticas divergentes los poetas del propio

5. Cf. Josep Fontana, La historia después del fin de la historia, Barcelona, Crítica, 1992. Esta crisis que afecta a la historiografía es patente a través de la fragmentación de la historia como " asignatura " en distintas ramificaciones parcialmente autónomas : historia social, historia económica, historia de las religiones, historia cultural, historia de las mentalidades, etc., cuando se olvida que el tronco común es la historia política, considerada en su aspecto dialéctico desde los centros de decisión hacia la base, pero sin menoscabar el efecto de retorno desde la base sobre las élites.

6. Para las citas procedentes del libro reseñado, indicaremos en adelante entre paréntesis las inciales LB seguidas de la página.

7. Al valorar el aporte de los poetas sociales, los novísismos se mostraron injustos y tendenciosos ante los notables cambios estéticos de las producciones de José Hierro, J. M. Caballero Bonald, R. Morales, por citar autores con obra conclusa. 
grupo de promovidos por José María Castellet ${ }^{8}$. La diversidad estética y los planteamientos dispares sobre la funcionalidad del lenguaje y su lugar en el campo social explican la bipolarización entre poetas de la experiencia y los poetas metafísicos (aunque establece aquí Luis Bagué una nómima más que discutible como veremos a continuación) cuya divisoria estética -si es que se pueda acudir a este tipo de reduccionismo al cual me atrevo) opone la lírica realista con la lírica abstracta. Pero esto no significa que bajo ambos estilos no haya que buscar una poesía " pensativa " o " especulativa ", venas por las cuales corren las razones del compromiso. Luis Bagué indaga a través de los recorridos azarosos de las filiaciones y herencias los signos del resurgimiento de una postura literaria cuya base es fundamentalmente ética. Lo que vino a significar - pero el autor no centra su atención en este fenómeno- que la vuelta al compromiso responde a una exigencia exterior a la literatura (como se nota hoy en día en el particular protagonismo de la novela de la memoria). Y sólo en segundo lugar -aunque para los estudiosos de la literatura, esto tendría que ser lo esencial- el escritor busca los medios apropiados para plasmar tales exigencias éticas. Pese a los discursos que pretendían que el escritor no tenía por qué someterse a una doctrina preexistente y que todo se elabora al filo de la escritura, queda excepcional el caso de los poetas capaces de sustraerse a la efervescencia colectiva que caracteriza los momentos de tensión de la sociedad a la que pertenecen (transición democrática, referendum de adhesión a la OTAN, guerra contra Irak, disfunciones de la sociedad liberal, etc.). De modo general, la preocupación por el entorno socio-político constituye síntomas claros de una vuelta al humanismo con resonancias muy contemporáneas, un humanismo que el culturalismo había desdeñado en su etapa fundacional. Observando las evoluciones de los culturalistas y sus seguidores, Luis Bagué apunta, en la década de los 70, cambios que muestran un terreno abonado por la rehumanización de la poesía : "la meditación sobre el paisaje revolucionario sesentayochista, la apertura al intimismo y el impulso sentimental" (LB, p. 42). A finales de los años 80 , salen antologías, libros colectivos, artículos críticos que sintetizan distintas corrientes cuyas propuestas firman el acta de defunción de los postulados novísimos iniciales, entre los cuales Luis Bagué destaca tres líneas bien identificables : la poesía de la experiencia, la poesía metafísica, la poesía de la diferencia.

Es normal que la poesía de la experiencia ocupe un sitio central a la hora de explicar los nuevos planteamientos del compromiso. Luis Bagué explica detenidamente el papel de transmisor desempeñado por Gil de Biedma que

8. J. M. Castellet, Nueve novísimos, Barcelona, Seix Barral, 1970. 
fue quien introdujo en España el concepto creado por Langbaum a propósito de la poesía inglesa de los siglos XIX y XX y quien aplicó el concepto a su propia obra y la de ciertos compañeros de generación. A la hora de pensar cuál era la índole del yo lírico, propugnaba la idea de una puesta en escena de un personaje que protagoniza sus poemas con su propia biografía o inventa situaciones derivadas de ella. De ahí el recurso frecuente a nivel retórico al monólogo dramático. Fuera de los rasgos estilísticos y tonalidad general (vuelta a un lenguaje figurativo y regreso de la narratividad, LB, p. 53) que bien podrían aplicarse a etapas anteriores de la poesía, no se avanza ninguna definición satisfactoria de la experiencia. Víctima acaso de la teoría desarrollada por Lejeune en El pacto autobiográfico, L. Bagué considera el discurso lírico como "un tipo especial de ficción" (LB, p. 54), postura no reconocida unánimemente por los poetólogos. Hace algún tiempo ya, había avanzado yo une definición escueta de la poesía de la experiencia, que ahora quiero recordar : "trátase de una poesía centrada en el conocimiento del sujeto a través de los contactos singulares que el poeta mantiene con la vida cotidiana " ${ }^{9}$. Apoyándonos en el ejemplo, no hemos podido sino constatar que los llamados temas " específicos " de la experiencia sacaban su interés del desfase entre la experiencia y su ideación. Frente a una difícil definición de la experiencia aplicada a una corriente de la poesía española -por la amplitud que abarca el concepto-, los críticos no tienen otro recurso que definir un paradigma con las constantes estilísticas que configuran una base estética común ${ }^{10}$, que harto repetidas acabaron por fosilizarse en los topoi urbanos y cotidianos. Lo que sí abre Luis Bagué es una perspectiva nueva al vincular la experiencia con la noción de complicidad defendida e ilustrada por Luis García Montero desde su Diario cómplice (1987). El diálogo que entabla el poeta con sus lectores potenciales vuelve a poner en el centro del debate sobre el compromiso el interés por la comunicación y los poderes o no poderes de la poesía. Luis Bagué analiza detenidamente la utilidad de la poesía tal como la piensa Luis García Montero para matizar mucho la insuficiente elaboración que se le reprochaba a la poesía en tiempos del social-realismo. Al plantearse una nueva forma de compromiso, la poesía abandona el terreno estrictamente político para ceñirse a una exigencia ética. Hoy se trataría de pensar " una utilidad situada a medio camino entre el concepto ilustrado de moral privada y el concepto materialista de conciencia cívica" (LB, p. 58). Tiene razón Luis Bagué cuando le atribuye a Jaime Gil

9. C. Le Bigot, «La poésie de l'expérience : figure de soi, figure de l'autre » in Europe, Voix d'Espagne, Paris, août 2000, nº 852, pp. 117-131.

10. Va por los mismos derroteros el trabajo de Araceli Iravedra en su voluminosa introducción a la antología Poesía de la experiencia, Madrid, Visor, 2007. 
de Biedma una inflencia decisiva en los poetas de la experiencia (Luis García Montero, Carlos Marzal, Felipe Benítez Reyes, Benjamín Prado). Y en su manera de enfocar el compromiso. Cabe recordar que el propio Jaime Gil de Biedma fue a principios de 1962 uno de los detractores más contundentes del social realismo, al poner en tela de juicio el alcance político de la poesía -cercano al cero-. Si el discurso lírico tiene alguna capacidad sería el ser un instrumento de análisis de la subjectividad, de ahí la propensión a indagar la sentimentalidad para mostrar in fine que no puede sustraerse a las leyes de la historicidad.

En su panorama de la poesía de los años 80/90, Luis Bagué deja un espacio a la poesía metafísica (p. 73 a 86), acaso por pruritos de exhaustividad, ya que la problemática del compromiso parece en esta etapa de su libro un poco disfuminada. El autor entra en distintas matizaciones legítimadoras y orientadas hacia las corrientes que expresan la búsqueda de trascendencia. Pero acaba por reconocer que en España el marbete de " poesía metafísica " abarca " un espacio poco acotado conceptualmente " (LB, p. 52). Desde luego, la poesía del silencio (declinada en distintos parámetros : poética del silencio, retórica del silencio) viene de lejos - desde la " música callada » de San Juan de la Cruz, para pervivir en la prolongación mística, aunque traspasada a otras áreas de la espiritualidad, lo judaico en el J. A. Valente de Tres lecciones de tinieblas (1980) y El fulgor (1984). En esta línea que es heredada de Paul Celan, Ungaretti y Mallarmé, se cita al Jaime Siles de Alegoría (1977) y Música de agua (1983), a Sánchez Robayna (La Roca, 1984) ; podría añadirse en esta veta a Miguel Martinón (Actos, 1988) como ejemplo de una poesía que acude a un grado extremo de condensación formal y gusto por un verso breve muy distinto de la cancioncilla. Pero lo que pudo haber dado cohesión a este epígrafe en relación con el compromiso es la crítica del lenguaje, no como tema autorreferencial o tema ontológico, sino como " performance " en su dimensión pragmática como puede ser la elipsis o el sobrentendido, lo que los " poetólogos " llaman la voz bajo las palabras, "la voz capaz de convertirse en la voz de los hombres que una barrera separó " como lo dice Adorno en sus Notes sur la littérature ${ }^{11}$. Adorno asocia la palabra lírica con la idea de una restauración de la comunicación mutilada en una sociedad alienada. En la opinión de Adorno se baraja la posibilidad de que en el lirismo moderno se oye un absoluto de que carecen los hombres en un mundo totalmente " administrado ». La dificultad para el poeta es "preservar la integridad del lenguaje sin tener que pagar el tributo del esoterismo " ${ }^{12}$.

11. Adorno, Notes sur la littérature, trad. Sibylle Muller, Flammarion 1984, p. 52-53.

12. Adorno, op. cit., p. 55. 
Más interesante nos parece el epígrafe dedicado a "la poesía de la diferencia " (LB, p. 86-95) que resume la polémica que opuso el grupo de los poetas noclónicos, incluidos en la antología Elogio de la diferencia, apoyado por el colectivo Alicia Bajo Cero y el grupo de los poetas de la experiencia cuyo mentor fue en el momento de la reyerta Felipe Benítez Reyes ${ }^{13}$. En concreto, los defensores de la poesía de la diferencia denunciaban la esclerosis de la poesía de la experiencia totalmente asimilada por la cultura oficial y promotora de nuevas torres de marfil que ahora "toman el aspecto de vagones de tren, salas de aeropuerto y habitaciones de hotel $»$. Recordando las críticas formuladas por los autores de Alicia Bajo Cero acerca de Habitaciones separadas de García Montero, Luis Bagué quiso recalcar el paulatino abandono de la crítica social a favor de un ensimismamiento en el que la domesticidad corre el riesgo de diluirse en la domesticación del personaje. Así es como Jorge Riechmann, miembro del colectivo, achacó a los poetas de la experiencia el autocultivo de una nostalgia juvenil asimilable a una ideología de trampantojos en la que la trivialidad noctívaga se ha sustituído a las estampas culturalistas de los novísimos. Con buen tino, Luis Bagué ve en los ataques de los poetas de la diferencia contra los poetas experienciales una repetición de los embistes que los novísimos propinaron a los autores del socialrrealismo. Al fin y al cabo uno puede preguntarse si la polémica entre los dos grupos no es el efecto de un afán de emulación frente al compromiso más eficaz, o sea no susceptible de recuperación. De manera humorística, podría decirse que los anatemas lanzados contra la poesía de la experiencia se cifran en la fórmula : "Plus engagé que moi tu meurs". La tentativa para acotar el grupo experiencial en una área controlada por el poder político fue como disparar al aire; fue patente con la antología Elogio de la diferencia ${ }^{14}$, cuya nómina de 35 autores venía encabezada por un cuestionario contestado por todos los antologados para que diesen su opinión sobre la relación entre poesía y cultura oficial, sobre los « reconocimientos públicos », sobre el discutible valor operativo del método de las generaciones.

Con el capítulo III (Perspectivas teóricas del compromiso en la última poesía española), entramos en el meollo de la problemática planteada por el título de libro. Acaso no sea inútil recordar que el grupo poético de la « otra sentimentalidad» se gestó en el clima culturalmente granadino de los finales de los setenta bajo la influencia del magisterio de Juan Carlos Rodríguez que

13. Cf. La serie de artículos publicados en Claves de Razón Práctica, $\mathrm{n}^{\circ} 58, \mathrm{n}^{\circ} 60, \mathrm{n}^{\circ} 61$ en que se opusieron Felipe B. Reyes por un lado y por otro Pedro J. de la Peńa y Antonio Rodríguez Jiménez.

14. A. Rodríguez Jiménez, Elogio de la diferencia. Antología consultada de los poetas no clónicos, Córdoba, Cajasur, 1997. 
introdujo a los jóvenes autores al pensamiento de Althusser et P. Macherey. Luis García Montero y Álvaro Salvador hicieron suyas las tesis del maestro que abogaba a favor de la radical historicidad de la literatura y mostraba la bifurcación nacida de la sociedad industrial en que la poesía o bien se orientaba hacia la estilización de la vida o bien optaba por la cotidianización de la poesía. La " otra sentimentalidad " se cimentó en la segunda opción, promoviendo un discurso solidario en el cual la representación de la intimidad interfería con la preocupación por las aspiraciones éticas de la colectividad. Con esto, la " otra sentimentalidad » entronca con parte de la generación del 50 (Ángel González, José Hierro, J. A. Goytisolo, J. M. Caballero Bonald) adoptando de ella el tono conversacional, la introspección distanciada y a veces lírica del personaje poético, y un enraizamiento urbano con telón de fondo experiencial. "La aceptación de la historicidad de la literatura conduce a la recuperación del compromiso" escribe Luis Bagué (p. 107). Pero esta vez, el poeta no es un visionario que se proyecta en una sociedad futura sino que piensa expresar una posición política concreta para influir en el presente. De ahí la importancia del recurso a un personaje poético que se parezca al " hombre de la calle », para que actúe plenamennte el fenómeno de identificación, como se puede observar frecuentemente en la obra monteriana.

Como complemento de la poesía de la experiencia, Luis Bagué analiza el lugar ocupado por la " poesía entrometida " cuyo representante más relevante es Fernando Beltrán, a través de sus proclamas y poemas. Si esta poesía conserva su voluntad testimonial y su afán acusatorio, se diferencia de la poesía social de los años 50/60 que pretendía " cambiar la sociedad ", ésta apela a una conciencia colectiva, víctima de las disfunciones del entorno porque queda bien claro el reparto de las responsabilidades, más allá de la simple dicotomía entre buenos y malos, pueblo y burguesía. Si esta poesía tiene un alcance social será por su manera de plantear las relaciones humanas, atacándose al enquistamiento provocado por las falsedades de la sociedad liberal y la capa de insolidaridad que las envuelve. La poesía puede actuar como un revulsivo que hace sospechar los reclamos de la sociedad de consumo. El poeta busca el modo para propiciar desconfianza y dudas en su lector. Este es el sentido de la "poesía entrometida " con el que " el poeta anda siempre por el medio, es un incómodo testigo de lo que ocurre " ${ }^{15}$.

15. Cf. Leopoldo Sánchez Torre, "Notas sobre la poesía de Fernando Beltrán », prólogo a El hombre de la calle de F. Beltrán, Granada, col. Maillot amarillo, 2001, p. 23. 
Como apoyo a las posturas defendidas por F. Beltrán, Luis Bagué enlaza la poesía entrometida con el realismo de indagación promovido por Jorge Riechmann. Desde su primer libro Cántico de la erosión (1981), en el cual la metáfora de la erosión apuntaba el desgaste progresivo de la poesía de combate de cuño antifranquista, y ya instalada la democracia en España, ese modelo necesitaba una relectura, ya que no se puede pasar por pérdidas y ganancias la cuestión de la comunicación ni de la permanencia de la conciencia crítica bastante embotada por el desarrollismo y el bienestar (siempre relativo para la inmensa mayoría). De una manera u otra, se reactiva el principio de una " poesía para despertar " pero esta vez fuera de las ideologías políticas que se enfrentaron durante el siglo XX (marxismo VS capitalismo), -aunque en el caso de Riechmann y otros autores ligados con colectivos, asistimos a un nuevo desplazamiento donde lo cívico se sustituye a lo político (altermundialismo VS neo-liberalismo). La cuestión que se plantea ahora es saber si la poesía en la sociedad postindustrial tiene suficiente capacidad para propiciar "la conformación de una nueva razón autocritica y resistencial» (LB, p. 128) para sortear el escollo de la poesía social que quiso « hablar por aquéllos que no pueden hacerlo ». Pese a las precauciones de Riechmann, nos podemos preguntar si el poeta comprometido no está cultivando una utopía del presente, variante del Sísifo de Camus al afirmar que " en la moderna sociedad burguesa toda la poesía tiene un componente político, pues estimula el diálogo y la formación de conciencia en torno a problemas vitales ". Hace falta reconocer que tal aserción tiene validez sólo para quien asigna a la poesía un poder corrosivo contra el efecto arrollador del pensamiento único. Por eso, J. Riechmann vuelve a plantear la cuestión de la forma, como una manera de resistir a las tentativas de asimilación de la maquinaria capitalista. No es inocente que Riechmann saque a relucir la antigua antinomia asentada por Neruda desde su proclama de 1935 "Sobre una poesía sin pureza ». Riechmann opta por admitir la radical impureza de su labor poética y ve en las palabras manchadas por la realidad una forma de resistencia a cualquier recuperación, colocando la poesía en el campo de un realismo crudo que se manifiesta a través de procedimientos de distanciación de alta intensidad (la irrisión, lo grotesco, lo cínico, lo paródico), las violencias inaceptables del mundo o denunciando los efectos de letargo a los que puede conducir el culto a la belleza. Tal postura puede cifrase en un poema emblemático de Cuadernos de Berlín (1989) con el cual su autor parodia el estilo periodístico, marcando su voluntad de rechazo de las modalidades estetizantes : 


\author{
RiEsGOS DEL ESTETICISMO \\ El cadáver no mostraba \\ señales de lucha. \\ Se le halló sin objetos personales \\ que pudieran facilitar su identificación. \\ Nada más que otro ahogado \\ en el proceloso piélago de la Belleza ${ }^{16}$.
}

El realismo sucio, como lo recuerda Luis Bagué, surgió en sus inicios como una corriente opuesta a la finalidad cívica de la poesía entrometida. Compartía con ella temas idénticos o afines, interesándose particularmente por los marginados para recabar los aspectos más degradados de la sociedad actual : droga, prostitución, mendicidad, marasmo moral que afecta a una juventud sumida en la desesperanza y el nihilismo, sin tabla de salvación. El realismo sucio adopta muchas veces un lenguaje coloquial, incluso vulgar, procedente del argot, patrimonio privativo de las tribus urbanas. Los poemas de Roger Wolfe cultivan un escepticismo total ante eventuales soluciones políticas. De modo que la recuperación de la lírica comprometida por el realismo sucio, "entre la subjetividad y la conciencia social " no puede ser sino " una de las tendencias más heterodoxas " como lo avanza Luis Bagué, sin aclarar verdaderamente la paradoja. (LB, p. 151). En la misma línea, resulta sorpendente la opinión más que favorable que le tributa García Posada a la poesía de R. Wolfe declarando que «transfigura la mediocre materia urbana en un discurso líricamente eficaz " ${ }^{17}$. Ni Bagué, ni García Posada vislumbran el escollo que amenaza al realismo sucio cuando busca su identidad en las hablas populares, argóticas, a través de situaciones convertidas en clisés del suburbio postindustrial. El llamado realismo sucio cae en el ready-made de la sordidez. Puede, sí, reivindicar la libertad de habla del personaje poético que acude a sonrojos socializantes. $Y$ en este caso la inventividad del realismo sucio es una protesta muy estilizada contra la instrumentación del lenguaje que no produce más que iconos des-realizantes -los que dibuja más que nunca la omnipotente ideología de la comunicación.

Con los capítulos IV y V, entramos en el estudio de la forma y de los temas que caracterizan la "nueva lírica social ", que es al mismo tiempo una manera de ampliar la visión y asentar los rasgos identificadores de la poesía comprometida. Lo que interesa al lector, al fin y al cabo, es saber si existen, tales rasgos -o dicho de otro modo- ¿ existen o no existen rasgos específicos del compromiso ? ¿A partir de qué momento reconoce el lector la variable

16. J. Riechmann, Cuadernos de Berlín, Madrid, Hiperión, 1989, p. 77.

17. García Posada, «En Babelia», El País, 19 de abril de 1993. 
cívica de un poema? A mi modo de ver, Luis Bagué concede un excesivo papel al cultivo del epigrama y de la sátira, que si son moldes frecuentemente utilizados por los poetas cívicos, no bastan para fundamentar una postura política. Ni tampoco puede considerarse operativa la extensión del poema para el asentamiento de un discurso moral «ajeno a la finalidad humoristica de los epigramistas" (LB, p. 174). Más interesante nos parece el "pacto realista " tal como lo piensa Jon Juaristi al apostar sobre una forma de complicidad entre poetas y lectores en el debate sobre la ética de la literatura. Sin embargo como excelente observador de las inflexiones que se produjeron en la historia de la poesía cívica, especialmente a finales de los años 80 , cuando ciertos postculturalistas iniciaron una vuelta a la rehumanización de la poesía (L. A. de Cuenca, Victor Botas, Jaime Siles), L. Bagué avanza las ventajas que se sacaron de una actitud distanciada frente al entorno ideológico. El caso de Víctor Botas con Historia antigua (1987) es explícito. De ahí las virtudes del epigrama : "En definitiva, el epigrama supone para los autores de los años ochenta un modelo de dicción que evita tanto la severidad didáctica como la lacrimosidad confesional, porque permite compatibilizar el reflejo de la realidad inmediata con cierto alejamiento emotivo " (LB, p. 172). Incorpora también L. Bagué en su trabajo las técnicas de collage e intertextualidad como procedimiento de desocultación de las ideologías predominantes (socialdemócrata o neoliberal) iniciados por poetas como Ángel González desde Breve muestra... o Prosemas o menos.

La tentación es muy fuerte de privilegiar entre los criterios de identificación de la poesía cívica una serie de temas nuevos como "la incomunicación urbana, la saturación tecnológica, la crónica de la marginalidad" (LB 191). $\mathrm{Si}$ estos temas no constituyen un criterio absoluto de la dimensión política de un discurso poético, tampoco se pueden ignorar por el valor colectivo que conllevan. Este aspecto va parejo con otro fundamental, aunque funciona más como resorte ideológico : es la memoria histórica que trasluce, incluso en las trayectorias personales de un Luis Antonio de Villena en Las herejias privadas (2001) cuya infancia y juventud fueron profundamente trastornadas por el ambiente asfixiante del franquismo. El mismo paisaje espectral asoma en Completamente viernes (1998) de L. García Montero. Todas estas relecturas del pasado encuentran hoy en día -y, hay que decirlo, como consecuencia de la democracia- ecos para medir el impacto demoledor del pasado cesarismo. La ciudad -cuya presencia en poesía adquirió cartas de ciudadanía con Ángel González, Carlos Barral, José Agustín Goytisolo- hoy en día invade el horizonte hasta definir una tupida red de nuevos tópicos que son específicos de la actual poesía española (alteridad, malditismo, marginación) cuyos contornos exceden forzosamente el terreno de lo 
político. Los temas de denuncia no faltan ; incluso en la opinión del autor se han internacionalizado (¿efecto de la globalización ?). Pongamos por ejemplo : la conciencia ecológica, el militarismo internacional, la revisión de los espejismos democráticos, la crónica de la marginación. La clave está acaso en la idea rotulada por L. Bagué cuando habla de los "nuevos temas de denuncia " (LB, p. 229). La denuncia sería un grado más elevado que el testimonio, apuntando los efectos perjudiciales de situaciones ínicas. Entonces, ¿puede generar la poesía una actitud cívica a partir de una perspectiva testimonial ? ¿Cómo salir de una aporía que ve en la literatura una forma de acción forzosamente limitada, pero tampoco inocua?

Finaliza este voluminoso análisis el examen detenido de cuatro poemarios ilustrativos de la nuevas formas del compromiso. Se trata de El día que dejé de leer El Pais (1997) de Jorge Riechmann, de Cinco años de cama (1998) de Roger Wolfe, de La semana fantástica (1999) de Fernando Beltrán y de La intimidad de la serpiente (2003) de Luis García Montero. En cada epígrafe, Luis Bagué propone una lectura coherente y bien argumentada, en la estela de lo que demostró en los capítulos anteriores a nivel teórico. El crítico pone especial atención en ofrecer a sus lectores un elenco suficientemente amplio de temas de raigambre social e ideológica, y sobre todo entra en el examen de los medios retóricos y estilísticos puestos al servicio de lo que L. Bagué llama "estética de la pobreza" o hiperrealismo crítico. En este sentido, apunta el crítico lo que Jorge Riechmann conserva de la tradición epigramática más antigua y analiza alguna que otra innovación que afecta al ritmo del verso libre apoyado en "los numerosos paralelismos y anáforas que remiten al fraseo repetitivo del blues" (LB, p. 269). Esta observación, si está fundada, merecería mayores explicaciones para ver cómo enlazan el ritmo y la temática de la resistencia o insumisión. Dado el recurso constante a fórmulas paródicas o a la ironía, no hubiera sido superfluo interrogarse sobre una radicalidad muy en sintonía con lo que desarrollaba un Guy Debord sobre la sociedad del espectáculo : la demistificación del imperio de la economía de mercado. A mi modo de ver, la obra de J. Riechmann y la de muchos poetas del hiperrealismo crítico van mucho más allá de la ferocidad de la sátira. El lector se encuentra ante una forma de pensamiento subversivo que se empeña en mostrar toda la nocividad de un sistema socioeconómico que muchos, incluso entre los menos favorecidos, creen virtuoso. Desde luego el discurso poético de J. Riechmann tiene que ser considerado a la luz de sus escritos teóricos, sin perder de vista que el impacto de esta literatura tiene sus límites igual que la militancia política en sus esfuerzos para establecer relaciones de fuerza con el poder. Lo mismo que denuncia el propio J. Riechmann en su poema «Desánimo del militante». 
Es obvio que L. Bagué quiso indagar más en los pormenores del hiperrealismo que caracteriza cierta vertiente de la actual poesía social al incluir en su libro un texto sacado de la obra de Roger Wolfe, representante del realismo sucio. Escoge en este caso Cinco años de cama para enfocar los tremebundos rasgos que configuran el tedio moderno desde el cual se define la postura existencial de R. Wolfe. Acierta el crítico en mostrar cómo el radical escepticismo del poeta es fruto del hundimiento de las certezas filosóficas propias de la posmodernidad, y el desengaño ante el desmoronamiento de los valores sociales. Pero frente a lo que podía sustentarse a base de datos personales, la experiencia propia sufre una inflexión hacia una mayor extensión de la preocupación social. No cabe duda de que el recurso más usado es la busca de una formulación que tiende al aforismo pero traspasado las más veces por la ironía para quitarle el cariz aleccionador, como se puede juzgar por la cita siguiente : "El problema no es / que la meta sea el olvido./ El problema es más bien / que al paso que vamos / no va a haber tiempo/ ni para eso." Hay mucho descaro en tales posturas que reivindican un prosaísmo, un "tono menor, a ras de suelo" (LB, p. 280) que acaba con la sacralidad de la poesía. Pero al mismo tiempo, R. Wolfe sabe mantener a distancia los dogmatismos ideológicos para entregar a sus lectores un nuevo calidoscopio sobre una cotidianidad fea, adulterada y desesperanzadora que cifra la inquietante quiebra del humanismo. Insiste L. Bagué en la postura de francotirador de R. Wolfe cuyo discurso es regido "por un imperativo ético que proclama una insumisión activa como respuesta a su insatisfacción moral» (LB, p. 282). Si la línea general seguida por L. Bagué nos parece acertada, acaso falta un análisis más elaborado de lo que significa la negatividad del realismo sucio. En el afán de deconstrucción de los clisés de la vida cotidiana, especialmente en estos " trozos de vida " que capturan los media y la publicidad, el tratamiento mordaz, incluso obsceno a veces, prosaico y demoledor, refuerza los efectos de agresividad que busca la poética de Wolfe cuyas dudas ante la utilidad de la poesía se hacen cómplice de un crimen contra la poesía, necesaria para darle nuevas exigencias. El caso del realismo sucio es una postura límite que si expresa plenamente la desazón existencial, contiene una dosis de malditismo que exige una superación estética. La tesis de una vuelta a la condensación expresiva del epigrama sólo cubre parcialmente la negatividad que conlleva el realismo sucio.

Entre los poemarios analizados, La semana fantástica de Fernando Beltrán (1999) acaso es el que mejor encaja con el género de la poesía cívica, dada su insistencia en una temática social inmediatamente identificable y que aneja temas candentes en el actual horizonte geopolítico : la inmigración (de africanos en pateras de fortuna), la marginación debida al desempleo, las 
guerras, los genocidios de Ruanda, las catástrofes ecológicas). Si la temática viene inspirada ampliamente por las disfunciones de la globalización, F. Beltrán aúna las contradicciones de un mundo global convertido al modelo capitalista, con los efectos que afectan a la trayectoria individual del personaje anónimo del libro. Pese a las precauciones que pone Luis Bagué en diferenciar la poesía « entrometida » de F. Beltrán y los poetas de la experiencia, creo que es difícil no reconocer cierta filiación con los planteamientos teóricos que reivindica Luis García Montero y con él la poesía de la experiencia al defender el principio de la historicización del sujeto y de los sentimientos. Quiero recordar tan sólo unas líneas escritas por García Montero en 1984 : " La aceptación de que toda literatura dibuja una moral, y la desdibuja en la medida de lo necesario para hacerla utilizable cotidianamente, le otorga a la intimidad un carácter histórico, y a los sentimientos un signo de frente en el que se puede guerrear ${ }^{18}$. Esta postura queda muy presente en la obra de F. Beltrán, incluso llevada a sus mayores extremidades, tras la máscara del personaje poético ; el artificio en este caso borra las fronteras entre la intimidad y la realidad social. Por otra parte, a la hora de considerar la especificidad de los recursos estilísticos al servicio de un trabajo ideológico se pudo haber interpretado cierta forma de desautomatización del discurso (LB, p. 309) como un signo de radicalidad propia de las nuevas formas del compromiso. "Escribir hoy -como dijo Christian Prigent, preguntado sobre la "valorización de la vulgaridad "- es intentar hacerse con los medios de un esfuerzo de simbolización desvinculado de la norma des-realizante " ${ }^{19}$. El compromiso de los poetas estudiados en este último capítulo consiste en crear espacios de lenguaje heterogéneo, que mezclan las tonalidades, donde lo bufo puede lindar con lo especulativo, la parodia con el lirismo. Desde esta espesura heterogénea puede surgir algo de la complejidad de la experiencia y darle cierta buidez a la « poesía entrometida ».

Luis Bagué termina su análisis del compromiso con La intimidad de la serpiente de Luis García Montero (2003). Es reflejo natural y justificado la incorporación del poeta granadino en el muestrario más elocuente del compromiso a comienzos del nuevo milenio, tanto más que la obra monteriana reivindica desde hace mucho el replanteamiento del compromiso al hacer compatibles los dos polos opuestos de historia pública e historia privada, al reconciliar intimidad lírica y proyección colectiva. Después de haber aclarado el sentido alegórico del título, en cuanto que la reminiscencia de la

18. Cf. L. García Montero, «La historia en voz baja de una nueva poesía » in Confesiones poéticas, Granada, Maillot amarillo, 1993, p. 192.

19. In À quoi bon la poésie, aujourd'hui ?, dir. por Claude Le Bigot, PUR, Rennes, 2007, p. 132. 
serpiente apuntaría no tanto la conciencia moral como la concientización, L. Bagué analiza el poemario examinando la adecuación entre las posturas teóricas de L. García Montero y su práctica poética, especialmente el paso de la escenificación del yo a la percepción de un cuerpo civil contemporáneo. Lo que permite enfocar bastantes temas de sociedad a través de inquietudes individuales que funcionan como metonimias de conflictos, aspiraciones contradictorias, sueños y renuncias. Si gran parte del análisis de L. Bagué aclara bien la construcción del personaje poético, sabiendo desentrańar lo que conlleva la poesía lírica de autobiografía en relación con la historia de España, echamos de menos la insuficiente visibilidad de una articulación entre voz poética y sentido político, que, a nuestro parecer, ya no se sitúa a nivel de una militancia (como lo recuerdan las propias palabras de L. García Montero citadas al pie de la página 315) sino a nivel del funcionamiento ideológico de la poesía en el campo literario. Tal vez le falte al libro de L. Bagué de vez en cuando una incursión en la perspectiva sociológica que hubiera aclarado el compromiso de la actual poesía espańola. En el estudio de los poemarios seleccionados, el lector se encuentra ante una aproximación contenidista adosada a un fino análisis estilístico muy útil, pero demasiado tributario de la historia del epigrama y la sátira (véase el capítulo IV). En el caso de L. García Montero, el peso de la tradición literaria y la remodelación de la voz lírica se conjugan de manera inequívoca. Pero ante un J. Riechmann, R. Wolfe, F. Beltrán, el lector descubre una auténtica ruptura (no creo que la palabra aparezca una sola vez en el estudio de L. Bagué) de lo que significó el lirismo. Para ellos, el lirismo es una vía sospechosa (no es el caso de L. García Montero). Lo que sí ostentan las producciones " realistas " es una capacidad de resistencia que consiste en huir de la vertiente edificante del lenguaje para indagar mediante una lengua rebelde y provocativa el gran desorden en el cual estamos involucrados.

En resumen y no obstante los reparos que se pueden poner sobre el método (según las preferencias teóricas de cada crítico) no podemos sino saludar la labor del investigador como aporte a una cuestión que está cobrando hoy en día un relieve inédito. Pues si la cuestión del compromiso atravesó la historia de la literatura española en sus momentos álgidos (República, Guerra civil, luchas antifranquistas), en época de democracia consolidada, los « modos del compromiso " van por otros derroteros. Esto lo demuestra con su inmensa cultura Luis Bagué (que además, no lo olvidemos, es buen poeta) ; contiene su libro muchas enseñanzas, más allá del tema axial, con un buen balance de una "poesía en pie de paz", pero al mismo tiempo escrita por poetas intranquilos en un tiempo neoliberal que no veía avecinarse el aluvión de quiebras. Ahora bien, cualquier debate sobre el compromiso de la literatura 
no puede olvidar lo que fue su origen en el entreguerra, en torno a la defensa de la cultura, y su teorización después de la Segunda guerra mundial por Jean Paul Sartre en Qu'est-ce que la littérature ? El filosófo francés había captado el riesgo y la tensión interna propiciados por su concepto del compromiso entre una literatura que se agarra a su autonomía formal y estética y la lógica de sumisión a la demanda externa (representada ampliamente a la altura de los años 50-60 por la estética del realismo social). Esta etapa está ya superada, pero no queda descartada la especificidad de la comunicación literaria que la poesía encarna en su grado más elaborado, y que parece situarse en los antípodas de la comunicación transitiva y eficaz (por eso J. P. Sartre no le atribuía en su ensayo posibilidades reivindicativas a la poesía). A la hora de valorar los modos de compromiso, no hay que perder de vista que para el escritor el único compromiso que no puede regatear es asumir la plena conciencia de los problemas de su propio lenguaje frente a la realidad que lo rodea. La cuestión de fondo entonces ya no es tanto el compromiso como la ética de la literatura.

Claude LE BIGOT 